\title{
Diagnóstico clínico e laboratorial da deficiência isolada do hormônio do crescimento em crianças e adolescentes portadores da mutação no gene do receptor do hormônio liberador do hormônio de crescimento em Itabaianinha, Sergipe

\author{
Clinical and laboratorial diagnosis isolated deficiency of growth hormone in children and adolescents with \\ mutation in receptor gene of growth hormone-releasing hormone in Itabaianinha, SE, Brazil
}

Carlos Alberto Menezes ${ }^{1}$; Valdinaldo Aragão²; Fabrício Rios-Santoss ${ }^{3}$; Manuel Hermínio Aguiar-Oliveira ${ }^{4}$

\section{unitermos \\ Deficiência isolada do hormônio \\ de crescimento \\ Hormônio de crescimento \\ Teste da clonidina \\ Teste de hipoglicemia insulinica \\ Itabaianinha}

Baixa estatura

\section{resumo}

Introdução: Em Itabaianinha - Sergipe é encontrado o maior grupo descrito na literatura de habitantes com o fenótipo associado à deficiência isolada do hormônio do crescimento (DIGH) em função da mutação IVS1+ 1, G $\rightarrow$ A no gene do receptor do hormônio liberador do hormônio de crescimento (GHRH). O objetivo do presente trabalho é descrever o fenótipo clínico e laboratorial dos pacientes da cidade. Materiais e métodos: Foram selecionados 12 indivíduos com fenótipo clínico de DIGH e 10 voluntários controles sem deficiência de $\mathrm{GH}$, ambos com idade inferior a 20 anos, para estudo de corte transversal. Resultados e discussão: Os portadores de DIGH apresentaram hiporresponsividade ao teste de clonidina e à hipoglicemia insulínica e níveis séricos abaixo dos valores de referência para o fator de crescimento insulina símile I (IGF-I) e proteína ligadora do fator de crescimento símile a insulina 3 (IGFBP- 3$)(6 \pm 4 \mathrm{ng} / \mathrm{ml}$ e $510 \pm 151 \mathrm{ng} / \mathrm{ml}$, respectivamente $p<0,01)$. O estudo mostrou não haver alterações de função tireoidiana, níveis de hormônios gonadais, cortisol e no estudo da sela túrcica nessa população. Os indivíduos de Itabaianinha apresentam maior número de características fenotípicas (baixa estatura proporcionada, facies típica, adiposidade central, etc.) quando comparados aos grupos descritos na literatura com outras mutações no GHRH-R. Conclusão: Os dados demonstram que a população da cidade apresenta deficiência isolada do hormônio de crescimento do tipo IB. Além disso, a baixa estatura não está associada a alterações múltiplas de hormônios hipofisários ou outras patologias não-hormonais.

\section{abstract}

Introduction: In Itabianinha, Sergipe, it was found the largest known population group with an IDGH associated phenotype, related to IVS1+1 mutation, $G \rightarrow A$ in the gene of GHRH receptor. The aim of the present work is to describe the clinical and laboratorial phenotype of these patients. Material and methods: Twelve young patients, under 20 years old, and 10 volunteer controls without the GH deficiency were selected for a transversal study. Results and discussion: IDGH individuals presented hyporesponsivity to the clonidine test and to the hypoglycemic insulinic test. Furthermore, they presented low levels of IGF-I and IGFBP-3 as compared with reference values (6 $\pm 4 \mathrm{ng} / \mathrm{ml}$ and $510 \pm 151 \mathrm{ng} / \mathrm{ml}$, respectively $p<0.01)$. There were no alterations in the thyroid, adrenal and gonad functions. The sella turcica study was also normal. The patients from Itabaianinha, when compared with other data of patients with GHRH-R mutations, were shorter, and presented characteristic typical facies and central adiposity. Conclusion: The results showed that the IDGH patients from Itabaininha presented a growth hormone isolated Type IB deficiency. In addition, the lower height was not associated with pituitary alterations or other non-hormone pathologies.

\section{key words} Isolated deficiency of

growth hormone

Growth hormone

Clonidine test

Insulinic hypoglycemy

Itabaianinha

Low height

\footnotetext{
1. Médico endocrinologista; mestre em Ciências da Saúde pela Universidade Federal de Sergipe (UFS); professor-assistente de Endocrinologia e Metabologia do curso de Medicina da Universidade Estadual de Santa Cruz (UESC).

2. Médico-cirurgião; professor-doutor da disciplina de Clínica Cirúrgica da UFS.

3. Farmacêutico; doutorando em Farmacologia pela Faculdade de Medicina de Ribeirão Preto/Universidade de São Paulo (FMRP/USP); professor-assistente de Farmacologia do Departamento de Saúde da UESC.

4. Médico endocrinologista; mestre e doutor em Endocrinologia pela FMRP/USP; professor-adjunto de Endocrinologia e Metabologia da UFS.
} 


\section{Introdução}

Itabaianinha é um município situado no centro-sul do estado de Sergipe que apresenta 30,8 mil habitantes, sendo 19 mil localizados na zona rural. Uma das características marcantes dessa população é a acentuada baixa estatura e a alta freqüência de consangüinidade. Fatores genéticos, que correspondem à maioria das causas de baixa estatura, ou fatores hormonais, poderiam explicar a deficiência nesses indivíduos.

Entre as causas hormonais que poderiam estar implicadas destacam-se: hipotireoidismo, síndrome de Cushing, raquitismo, pseudo-hipoparatireoidismo, as alterações do eixo hormônio liberador do hormônio do crescimento/hormônio de crescimento $(\mathrm{GHRH} / \mathrm{GH})$, por deficiência hipotalâmica e hipofisária, resistência do GH (síndrome de Laron), resistência ou deficiência do fator de crescimento insulina símile I (IGF-I), além das causadas por defeitos moleculares do eixo $\mathrm{GHRH} / \mathrm{GH} / \mathrm{IGF}-\mathrm{I}$, proteína de ativação transcricional (PIT-1) e prophet of PIT-1 gene (PROP-1) $(27-29,42)$.

Identificamos em Itabaianinha 105 indivíduos com idades variando entre 5 e 82, anos com baixa estatura e padrão autossômico recessivo decorrente de uma mutação no sítio de emenda guanina $\rightarrow$ adenina na posição +1 no íntron 1, no gene do receptor do $\mathrm{CHRH}^{(33)}$. Outras mutações no receptor do GHRH E72-X, como causa de deficiência isolada de $\mathrm{GH}$, foram descritas por Wajnrajch et al. (1996), Baumann et al., nos Anões de Sindh (1997), e Netchine et al. (1998) em dois irmãos da Índia ${ }^{(2,18,41)}$. O objetivo deste trabalho é descrever o fenótipo clínico e laboratorial dos pacientes de Itabaianinha. Os dados apresentados neste artigo descrevem os seus padrões antropométricos e laboratoriais e discute suas características clínicas quando comparados a outros grupos de indivíduos portadores da mutação E72-X.

\section{Material e método}

\section{Casuística}

Foram selecionados da região de Itabaianinha 12 indivíduos portadores de deficiência isolada do hormônio do crescimento (DIGH) de ambos os sexos e com idade inferior a 20 anos, e 10 voluntários controles não-portadores de $\mathrm{DIGH}$, utilizando um estudo de corte transversal durante um ano. Como base para critério da deficiência de $\mathrm{GH}$, além das confirmações genotípica familial e fenotípica clínica, foram utilizados dois testes farmacológicos e as dosagens de IGF-I e IGFBP-3.

\section{Diagnóstico laboratorial}

$\mathrm{O} \mathrm{GH}$ foi determinado pelo método imunofluorimétrico (Auto Delfia), tendo o limite mínimo detectável o valor aproximado de $0,01 \mathrm{ng} / \mathrm{ml}$ e coeficientes de variação intra-ensaio e interensaio de 3,7\% e $5 \%$, respectivamente. A técnica dos testes de liberação de $\mathrm{GH}$ inclui jejum, repouso e ausência de estresse. Foi utilizada clonidina na dose oral de $0,15 \mathrm{mg} / \mathrm{m}^{2} / \mathrm{sc}$, com veia periférica cateterizada, e foram coletadas amostras de sangue nos tempos 0, 30, 60, 90 e 120 minutos. Os pacientes foram monitorizados quanto a pressão arterial, freqüência cardíaca e sonolência.

Em relação à hipoglicemia insulínica foi utilizada a dose de $0,1 \mathrm{U} / \mathrm{kg}$ de insulina regular por via venosa, tendo o cuidado de reservar glicose a $25 \%$. Os pacientes eram colocados em repouso com veia periférica cateterizada, sendo colhidas amostras de sangue nos tempos $0,15,30$, 60 e 90 minutos. A glicemia capilar foi monitorizada para determinação do nível de hipoglicemia, definida como glicemia menor que $40 \mathrm{mg} / \mathrm{dl}$.

Resultados normais para a prova de estímulo do $\mathrm{GH}$ foram aqueles em que os níveis de $\mathrm{GH}$ alcançaram $10 \mathrm{ng} / \mathrm{ml}$ ou mais, sendo considerados não-responsivos os com níveis de $\mathrm{GH}$ inferiores a $3 \mathrm{ng} / \mathrm{ml}$. Para as respostas parciais, os níveis considerados foram os situados entre 3 e $10 \mathrm{ng} / \mathrm{ml}$. Para o cortisol, a resposta normal foi a duplicação do nível basal ou um dos valores maiores que $20 \mathrm{ug} / \mathrm{dl}$.

Para determinação dos níveis séricos de IGF-I pelo método imunorradiométrico, foram utilizados kits de diagnóstico comercialmente disponíveis (Active IGF-I DLS 6600, Diagnostic System Laboratories, Webster TX). A sensibilidade referida do método foi de $0,8 \mathrm{ng} / \mathrm{ml}$ e os coeficientes de intra e interensaio correspondem a 3,4\% e $8,25 \%$, respectivamente. Para determinação do IGFBP3 foram utilizados reagentes comerciais disponíveis para imunorradiometria (Active IGFBP-3 DSL 5600, Diagnostic System Laboratories, Webster TX). A sensibilidade referida do método corresponde a $0,5 \mathrm{ng} / \mathrm{ml}$, com coeficientes de variação intra e interensaio de $1,9 \%$ e $3,9 \%$, respectivamente.

Para as dosagens hormonais de T3, T4, cortisol e testosterona foram usados métodos de fluoroimunoensaio; para a determinação de hormônio folículo-estimulante (FSH), hormônio luteinizante (LH), hormônio estimulante da tireóide (TSH) e prolactina, ensaios fluorimunométricos. Todos os ensaios hormonais de rotina passaram por testes de controles interno e externo de qualidade e interlaboratoriais. 


\section{Ética na pesquisa}

A participação dos indivíduos selecionados no protocolo de investigação foi precedida da anuência dos mesmos, mediante a assinatura do termo de consentimento informado pelos pais ou pelo responsável, após aprovação do Comitê de Ética do Hospital Universitário da Universidade Federal de Sergipe (UFS).

\section{Estatística}

Através da média e do desvio-padrão (DP), foram avaliados dados clínicos e antropométricos de indivíduos controles e portadores de deficiência de GH em Itabaianinha. Foram utilizados os testes $t$ de Student e a análise de variância (one-way-ANOVA) para a comparação dos testes de estímulos de secreção de $\mathrm{GH}$ nos grupos com DIGH e no grupo controle. Os dados são apresentados como média \pm DP ou mínimo-máximo dos ensaios realizados. Considerou-se como significante um valor de $p<0,05$.

\section{Resultados}

Dos indivíduos com DIGH estudados, oito foram do sexo feminino e quatro do sexo masculino, com médias de idade cronológica de 13,1 anos, idade óssea de $8 \pm 4$ anos, altura de $111,2 \pm 3,4 \mathrm{~cm}$ e velocidade de crescimento de $2 \pm 1,5 \mathrm{~cm} /$ ano. $O$ índice de massa corpórea dos pacientes avaliados não apresentava indícios de obesidade infantil. As relações altura/envergadura, bem como vértice/púbis e púbis/planta, foram aproximadamente iguais a 1, o que demonstra a proporcionalidade da baixa estatura de todos os indivíduos portadores de DIGH avaliados. Outros dados antropométricos, como medidas vértice-púbis, púbis-planta, relação altura/envergadura, além da relação vértice/púbis e púbis/planta, encontram-se também representados na Tabela 1.

Nas Figuras 1 e $\mathbf{2}$ estão representadas as concentrações séricas de $\mathrm{GH}$ após os testes de estímulos de clonidina e hipoglicemia insulínica (ITT) de indivíduos portadores de DIGH e controles. A resposta máxima média aos testes de clonidina e hipoglicemia insulínica foi estatisticamente menor quando comparada à de indivíduos controles. Os portadores de DIGH apresentaram valores de 0,42 \pm $0,6 \mathrm{ng} / \mathrm{ml}$ e $0,2 \pm 0,2 \mathrm{ng} / \mathrm{ml}$ de $\mathrm{GH}$, respectivamente. Glicemia menor que $40 \mathrm{mg} / \mathrm{dl}$, no tempo de 15 minutos, foi observada em todos os pacientes durante o ITT. A avaliação dos níveis séricos de cortisol foi realizada mediante a sua dosagem basal e após o estímulo de hipoglicemia insulí- nica. Os resultados demonstraram duplicação dos níveis de cortisol em relação aos seus valores basais em todos os casos estudados (Tabela 2).

A Figura 3 apresenta os níveis de IGF-I e IGFBP-3 dos 12 portadores de DIGH ( $6 \pm 4$ e $510 \pm 151$, respectivamente) comparados aos seus controles, demonstrando uma concentração sérica significativamente menor em todos os indivíduos de baixa estatura analisados. A Tabela 3 apresenta o estudo do eixo gonadal avaliado através das dosagens de LH, FSH, estradiol e testosterona, sendo normais para o estádio puberal em todos os pacientes com DIGH. O estádio puberal das crianças do sexo masculino era P1G1, sem micropênis e com níveis pré-púberes de LH, FSH e testosterona, ou seja, níveis máximos de $0,3 \mathrm{uU} / \mathrm{ml}, 0,9 \mathrm{uU} / \mathrm{ml}$ e inferiores a $0,1 \mathrm{ng} / \mathrm{ml}$, respectivamente. Os indivíduos do sexo feminino foram divididos em dois grupos. No primeiro, quatro eram pré-púberes e intrapúberes P1M1-P1M2, com níveis máximos de LH, FSH e estradiol de $0,7 \mathrm{uU} / \mathrm{ml}, 3 \mathrm{uU} / \mathrm{ml}$ e $13,6 \mathrm{pg} / \mathrm{ml}$, respectivamente. O segundo grupo, composto por quatro indivíduos com puberdade completa (P5M5) e avaliado na fase folicular, apresentava níveis normais de gonadotrofinas.

Em relação à função tireoidiana não foram encontradas alterações significativas, como observado pelas médias e pelos desvios-padrão de T3 (1,83 $\pm 0,38 \mathrm{ng} /$ $\mathrm{ml})$, T4 $(9,88 \pm 3,06 \mu \mathrm{g} / \mathrm{dl})$ e TSH $(2,7 \pm 0,76 \mu \mathrm{U} / \mathrm{ml})$. A média da concentração sérica de prolactina $(12,2$ $\pm 3,04 \mathrm{ng} / \mathrm{ml}$ ) não apresentou diferença significativa quando comparada ao grupo controle. Em relação aos testes bioquímicos não foram encontradas diferenças entre valores de proteínas totais e frações, uréia, creatinina, cálcio, fósforo, fosfatase alcalina, transaminase glutâmico-oxalacética (TGO) e transaminase glutâmicopirúvica (TGP) em relação às médias de referência. No que diz respeito à pesquisa de parasitoses, os exames não apresentavam alterações. A avaliação urinária não revelou anormalidades.

A baixa estatura presente nos indivíduos de Itabaianinha foi caracterizada como proporcionada e pós-natal e associada a um aumento da massa gorda de distribuição principalmente truncal e a uma redução da massa magra. Os indivíduos apresentavam fronte proeminente (fáscies de boneca), de aspecto imaturo, órbitas rasas, raiz nasal hipoplásica, voz de timbre agudo e alto, cabelos finos e esparsos e pele lisa e prematuramente enrugada, corroborando os dados descritos em outros trabalhos ${ }^{(1,8)}$. 
Tabela 1 Dados antropométricos dos 12 indivíduos portadores de DIGH em Itabaianinha, Sergipe, 2003

\begin{tabular}{|c|c|c|c|c|c|c|c|c|c|c|c|}
\hline Nome & Sexo & $\begin{array}{c}\text { IC } \\
\text { (anos) }\end{array}$ & $\begin{array}{c}10 \\
\text { (anos) }\end{array}$ & $\begin{array}{c}\text { IE } \\
\text { (anos) }\end{array}$ & $\begin{array}{l}\text { EDP } \\
a / i\end{array}$ & $\begin{array}{c}\text { VC } \\
\text { (em/ano) }\end{array}$ & $\begin{array}{l}\text { Altura } \\
\text { (cm) }\end{array}$ & $\begin{array}{l}\text { ALT/ } \\
\text { ENV }\end{array}$ & VP/PP & $\begin{array}{c}\text { IMC } \\
\left(\mathrm{kg} / \mathrm{m}^{2}\right)\end{array}$ & $\begin{array}{l}\text { Peso } \\
(\mathrm{kg})\end{array}$ \\
\hline G.J.M. & M & 5,2 & 3 & 1,9 & $-4,47$ & 3 & 86 & 1,01 & 1,15 & 17,5 & 13 \\
\hline E.J. & M & 8,5 & 4,6 & 4 & $-4,24$ & 3,3 & 102,5 & 1,02 & 1,15 & 14,4 & 15 \\
\hline J.J.S. & M & 9,2 & 5 & 4,3 & $-4,73$ & 3,5 & 105 & 1,01 & 1,01 & 13,1 & 14,5 \\
\hline M.C.J. & F & 10,5 & 8 & 4,9 & $-4,91$ & 2,2 & 108,4 & 0,99 & 1,06 & 15,5 & 18 \\
\hline V.S.F. & $\mathrm{F}$ & 11,5 & 5 & 6,3 & $-4,44$ & 2,5 & 117 & 1,01 & 1,05 & 18,1 & 21 \\
\hline D.J.S. & $\mathrm{F}$ & 12 & 7,1 & 8 & $-2,67$ & 2 & 127 & 1,01 & 1,04 & 22,3 & 36 \\
\hline T.S. & M & 13,1 & 8 & 4 & $-6,75$ & 3 & 104 & 1,01 & 1,05 & 18,1 & 16 \\
\hline J.A.M. & $\mathrm{F}$ & 13,7 & 11 & 4,6 & $-7,05$ & 3 & 107,5 & 1,02 & 0,99 & 16,6 & 19 \\
\hline E.F.L. & $\mathrm{F}$ & 17 & 13,6 & 7 & $-5,9$ & 0,5 & 122 & 1,04 & 1,03 & 18,9 & 22 \\
\hline A.F.S. & F & 18 & 15 & 6 & $-7,35$ & 0,5 & 116,5 & 1,04 & 1,01 & 19,4 & 26 \\
\hline M.F.S. & $\mathrm{F}$ & 19,4 & * & 6,9 & $-7,03$ & 0,5 & 120 & 1,04 & 1 & 18,4 & 26,5 \\
\hline E.L.F.L. & $\mathrm{F}$ & 19,6 & 16 & 6,6 & $-7,2$ & 0,5 & 119 & 1,03 & 1,03 & 16,6 & 23 \\
\hline$X \pm$ & - & 13,1 & 8 & 5,4 & $-4,6$ & 2 & 111,2 & 1,02 & 1,05 & 17,41 & 21,3 \\
\hline $\mathrm{DP}$ & - & 4,6 & 4,2 & 2,1 & 3,6 & 1,5 & 3,4 & 0,02 & 0,05 & 2,42 & 7,7 \\
\hline
\end{tabular}

IC: idade cronológica; IO: idade óssea; IE: idade estatural; EDP a/i: escore de desvio-padrão de altura/idade; VC: velocidade de crescimento; ALT/ENV: altura/envergadura; VP/PP: relação vértice/púbis e púbis/planta; IMC: índice de massa corpórea; $X \pm$ : média; DP: desvio-padrão.

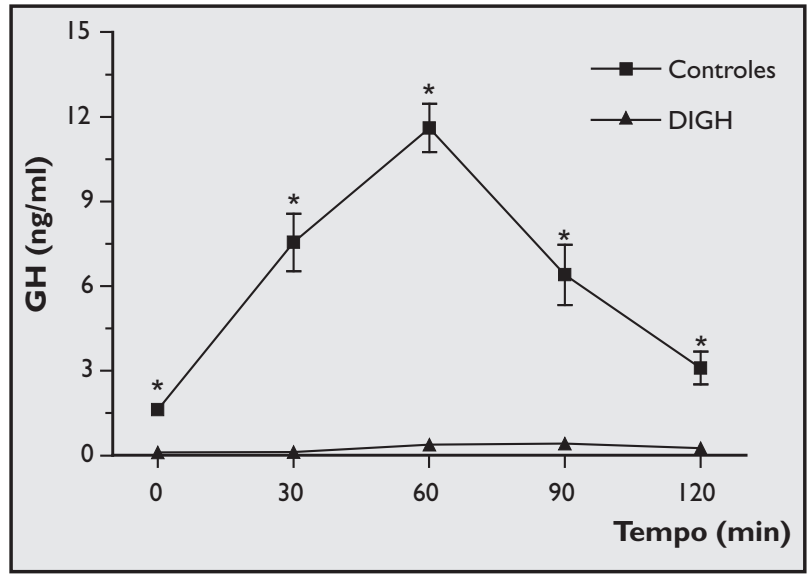

Figura 1 - Concentrações séricas de CH em indivíduos portadores de DIGH e controles após teste de clonidina em Itabaianinha, Sergipe, 2003. Foram determinadas as concentrações do $\mathrm{CH}(\mathrm{ng} / \mathrm{ml})$ em crianças com DIGH $(\mathrm{n}=12) e$ controles $(\mathrm{n}=10)$ após o teste com $0,15 \mathrm{mg} / \mathrm{m}^{2}$ de clonidina. Os resultados estão expressos como média \pm epm. ${ }^{*} \mathrm{p}<0,01$, segundo teste t de Student

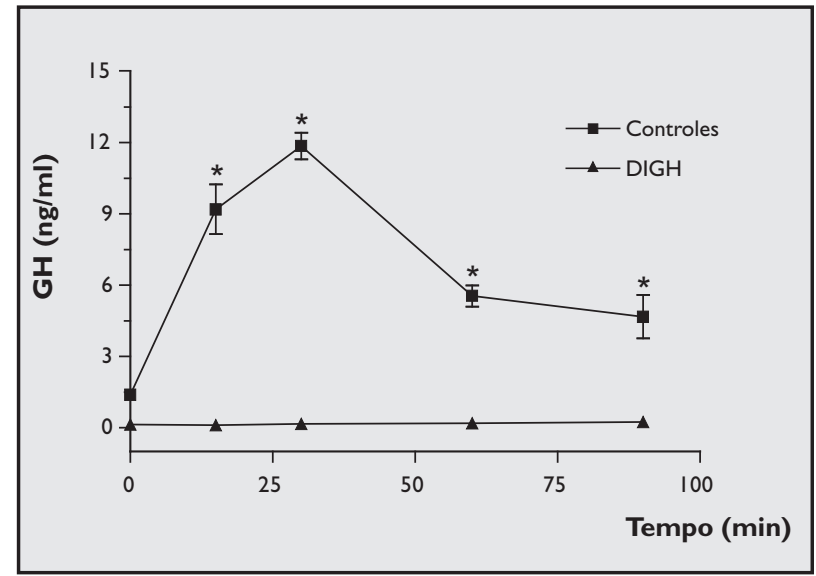

Figura 2 - Concentrações séricas de $\mathrm{CH}$ em indivíduos portadores de DICH e controles após teste de hipoglicemia insulínica em Itabaianinha, Sergipe, 2003. Foram determinadas as concentrações do $\mathrm{CH}$ em crianças com DIGH $(n=9)$ e controles $(\mathrm{n}=10)$ após o teste com $0,1 \mathrm{U} / \mathrm{kg}$ de insulina regular em infusão venosa. Os resultados estão expressos como média \pm epm. ${ }^{*} p<0,01$, segundo teste t de Student

e nos tecidos moles ${ }^{(3,22,26,37)}$. De fato, a DIGH corresponde à ausência ou à diminuição do hormônio do crescimento, sendo associado a fenótipos de baixa estatura. Como observado na Tabela 1, a população de Itabaianinha apresenta características antropométricas marcantes de DIGH, diferenciando-se de outras deficiências pelo maior número de características fenotípicas em um mesmo indivíduo. 
Tabela 2 Valores de cortisol de nove indivíduos portadores de DIGH em Itabaianinha, Sergipe, 2003

\begin{tabular}{lccccc}
\hline & \multicolumn{5}{c}{ Cortisol $(\mu \mathrm{g} / \mathrm{ml})$} \\
Nome & $0^{\prime}$ & $15^{\prime}$ & $30^{\prime}$ & $60^{\prime}$ & $90^{\prime}$ \\
\hline G.J.M. & 26,3 & 20,5 & 29,5 & 30 & 26,04 \\
E.J. & 27,3 & 25,8 & 26,1 & 29,9 & - \\
J.J.S. & 8,9 & 9,6 & 15,4 & 17 & 18,4 \\
M.C.J. & 35 & 28 & 29,5 & 30 & 28 \\
V.S.F. & 12 & 15 & 21 & 26,2 & 24,1 \\
J.A.M. & 12,7 & 11,2 & 22,9 & 23 & 27,7 \\
E.F.L. & 5,6 & 6,1 & 19,1 & 22,1 & - \\
A.F.S. & 9,5 & 10 & 18,1 & 21,7 & 18,1 \\
E.L.F.L. & 7,7 & 7,5 & 18,5 & 18 & 27,4 \\
X & 6,1 & 16,11 & 22,2 & 22,4 & 24,3 \\
\pm DP & $\pm 0,5$ & $\pm 8,06$ & $\pm 5,12$ & $\pm 8,94$ & $\pm 4,33$ \\
\hline
\end{tabular}

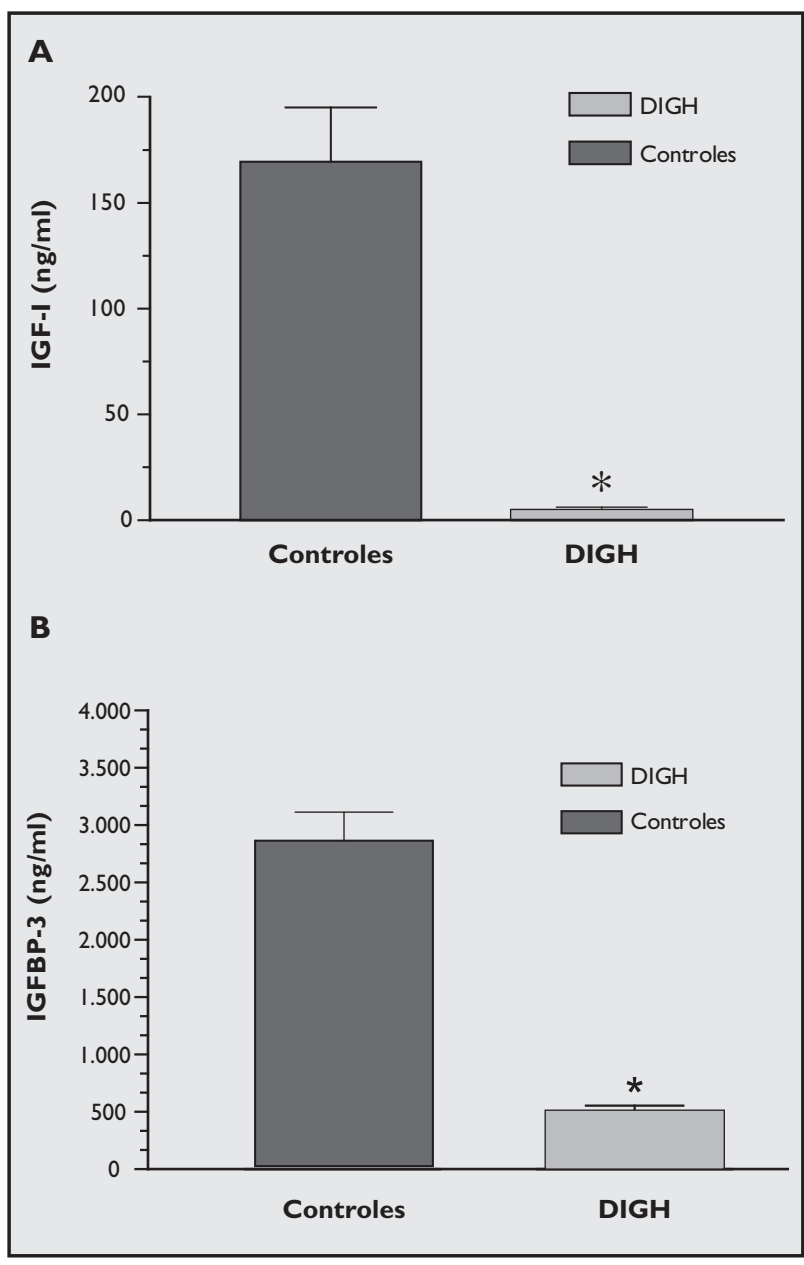

Figura 3 - Valores basais de (A) IGF-I e (B) IGFBP-3 em crianças e adolescentes com DICH e controles em Itabaianinha, Sergipe, 2003. Foram determinadas as concentrações séricas de IGF-I e IGFBP-3 em pacientes com DIGH $(\mathrm{n}=12)$ e voluntários sadios $(n=10)$ em jejum. Os resultados estão expressos como média \pm epm. ${ }^{*} p<0,01$, segundo teste t de Student
Os efeitos biológicos do $\mathrm{GH}$, em grande parte mediados pela produção hepática do fator de crescimento insulina símile I (IGF-I), podem ocorrer por ação direta do hormônio sobre o tecido ósseo. No sangue periférico, o IGF-I se associa às proteínas de ligação, principalmente a IGFBP-3, cuja síntese também é estimulada pelo $\mathrm{GH}^{(14,39)}$. Os indivíduos estudados apresentam valores séricos de IGF-I e IGFBP-3 significativamente menores quando comparados a controles. Essa redução reflete a dependência da síntese desses hormônios pelo $\mathrm{GH}$. A implicação clínica desse fato reside na observação de que a terapia farmacológica com a administração de $\mathrm{GH}$ exógeno melhora os aspectos fenotípicos de DIGH na população de Itabaianinha.

A dosagem do IGF-I foi a primeira das alternativas, ou complementos, dos testes de estímulos para o $\mathrm{GH}$, a ter uma ampla aplicação. Por se tratar de um peptídeo dependente de $\mathrm{GH}$ e ser seu efetor na maioria das ações biológicas, a lógica da sua dosagem para definição do diagnóstico da deficiência de GH é de fundamental importância(3, 14), sendo, portanto, um marcador altamente sensível para o diagnóstico da deficiência de $\mathrm{GH}^{(1,3)}$. No que diz respeito ao IGFBP-3, sua concentração sangüínea depende de alguns fatores como: estado nutricional e puberdade $(4,5,10,40)$.

Em relação às dosagens de IGF-I e IGFBP-3 dos pacientes estudados, todos os indivíduos apresentavam valores abaixo do referencial para as idades cronológica e óssea, o que corroborou o diagnóstico da deficiência de $\mathrm{GH}$.

Aguiar-Oliveira et al. ${ }^{(1)}$ estudaram os níveis de IGF-I, IGF-II, IGFBP-1, IGFBP-2, IGFBP-3 e a subunidade do ácido 
Tabela 3 Avaliação puberal dos 12 indivíduos portadores de DIGH em Itabaianinha, Sergipe, 2003

\begin{tabular}{cccccccc}
\hline Paciente & Sexo & IC & $\begin{array}{c}\text { Estádio } \\
\text { puberal }\end{array}$ & $\begin{array}{c}\text { LH } \\
(\mu \mathrm{U} / \mathrm{ml})\end{array}$ & $\begin{array}{c}\text { FSH } \\
(\mu \mathrm{UU} / \mathrm{ml})\end{array}$ & $\begin{array}{c}\text { Testosterona } \\
(\mathrm{ng} / \mathrm{ml})\end{array}$ & $\begin{array}{c}\text { Estradiol } \\
(\mathrm{pg} / \mathrm{ml})\end{array}$ \\
\hline 1 & M & 5,2 & P1G1 & 0,2 & 0,8 & $<0,1$ & - \\
2 & M & 8,5 & P1G1 & 0,2 & 0,8 & $<0,1$ & - \\
3 & M & 9,2 & P1G1 & 0,1 & 0,9 & $<0,1$ & - \\
4 & M & 13,1 & P1G1 & 0,3 & 0,9 & $<0,1$ & - \\
5 & F & 10,5 & P1M1 & 0,1 & 2,5 & - & 13,6 \\
6 & F & 11,5 & P1M2 & 0,7 & 2,8 & - & 12,5 \\
7 & F & 12 & P1M2 & 0,05 & 3 & - & 7,3 \\
8 & F & 13,7 & P1M1 & 0,8 & 5,2 & - & 3,4 \\
9 & F & 17 & P5M5 & 4,4 & 8,9 & - & 32,4 \\
10 & F & 18 & P5M5 & 3 & 8,5 & - & 48,8 \\
11 & F & 19,4 & P5M5 & 2,8 & 1,3 & - & 30 \\
12 & F & 19,6 & P5M5 & 1,2 & 6,8 & - & 26,3 \\
\hline
\end{tabular}

IC: idade cronológica; estádio puberal: pêlos, genitália e mama; LH: hormônio luteinizante; FSH: hormônio folículo-estimulante; testosterona: sexo masculino; estradiol: sexo feminino.

lábil (ALS) em 27 pacientes portadores da mutação do receptor do GHRH, em Itabaianinha, e concluíram que o IGF-I apresenta um poder diagnóstico superior ao da IGFBP-3, devendo ser o método de escolha na avaliação da DIGH ou na baixa estatura em geral.

A deficiência de $\mathrm{GH}$ pode ser isolada ou múltipla, idiopática ou associada a outras patologias, familial ou esporádica. Pode ser por defeitos moleculares no receptor do GHRH, no receptor do $\mathrm{GH}$, no receptor do IGF-I ou por alterações dos fatores de transcrição PIT-1 e PROP-1. As formas idiopáticas decorrentes de partos traumáticos, assim como a resistência à ação do $\mathrm{GH}$ (síndrome de Laron), também são conhecidas. Sobre esses aspectos, considera-se o fenótipo presente em Itabaianinha como uma deficência isolada, familial e molecular no receptor do GHRH. Tal consideração encontra apoio nos achados desse trabalho, nos quais não foram encontradas alterações nos níveis de outros hormônios hipofisários $(6,7,9,12,13,15,16,21,30,31,34-36,38,42)$.

A deficiência de $\mathrm{GH}$ também pode ser classificada com base no nível sérico e no padrão de herança determinante por desordens mendelianas. O tipo IA é caracterizado por um padrão autossômico recessivo, com nível de $\mathrm{GH}$ ausente e severo retardo do crescimento já presente nos primeiros seis meses de vida, às vezes associado a episódios de hipoglicemia. As crianças respondem bem inicialmente ao tratamento com $\mathrm{GH}$, mas muitas desenvolvem anticorpos
anti-GH, bloqueando a ação do hormônio recombinante e a resposta terapêutica.

Os defeitos genéticos são heterogêneos, incluindo vários tipos de deleções e mutações. Invariavelmente, essas falhas genéticas levam à ausência total da produção hipofisária de GH. O tipo IB se caracteriza por níveis plasmáticos baixos, porém detectáveis, de $\mathrm{GH}$, e uma boa resposta após tratamento exógeno com este, sem aparecimento de anticorpos bloqueadores. Os pacientes afetados com o tipo II apresentam sempre um dos pais com o problema, e a severidade das manifestações clínicas varia entre os parentes afetados. Embora diferentes mutações tenham sido descritas, todas, invariavelmente, localizam-se no íntron 3 e afetam a transcrição de todo éxon 3, responsável pela seqüência de aminoácidos 32-71 da molécula de GH. Por fim, o tipo III, com manifestações clínicas distintas, relacionado ao cromossomo $X$, pode em alguns indivíduos apresentar um quadro clínico de agamaglobulinemia associada à deficiência de $\mathrm{GH}$, além de retardo menta|(11,17,19,23-26). Avaliando o tipo de deficiência do $\mathrm{GH}$ apresentado no estudo, podemos afirmar que este é isolado e do tipo IB, pois não há sinais e sintomas de outras disfunções hipofisárias, e as dosagens de hormônios tireoidianos, gonadais, adrenal e prolactina foram normais.

É de fundamental importância análise morfológica através de ressonância magnética da região hipotalâmica e hipofisária contrastada com gadolínio no estudo da deficiência 
de $\mathrm{GH}$, pois podemos observar alterações como hipersinal em T1, além de neuro-hipófise ectópica e ruptura de haste hipofisária. Os pacientes de Itabaianinha avaliados pela ressonância magnética da região hipotalâmica e hipofisária, crianças e adultos com a mutação IVS1, $+1 \mathrm{G} \rightarrow \mathrm{A}$, demonstraram a presença de hipoplasia da pituitária isolada ${ }^{(20)}$.

Wajnrajch, Baumann e Netchine descreveram no subcontinente indiano a mutação $\mathrm{E} 72-\mathrm{X}$, comum na população de Itabaianinha, originada por uma troca de guanina por adenina no éxon 3 (GAG $\rightarrow$ TAG), induzindo um códon de parada no domínio extracelular do receptor do $\mathrm{GHRH}^{(2,18,}$ 41). Salvatori et al. ${ }^{(33)}$ identificaram na cidade a mutação homozigótica no sítio splice (guanina $\rightarrow$ adenina na posição +1) no íntron 1, no gene do receptor do $\mathrm{GHRH}$, no maior grupo descrito na literatura. Posteriormente, outra mutação LH 144 foi encontrada pelo mesmo grupo em outras famílias de Sergipe, na cidade de Aquidabã, EUA, México e Guatemala ${ }^{(32)}$.

Em relação ao grupo de Itabaianinha descrito por Salvatori, os pacientes apresentavam acentuada baixa estatura, com DP = 4,5 e fenótipo bastante característico da deficiência de $\mathrm{GH}$. Os amostrados não responderam aos testes de clonidina e ITT para avaliação hormonal do $\mathrm{GH}$. Os níveis séricos de IGF-I e IGFBP-3 estavam abaixo do referencial para as idades dos pacientes. Prolactina, TSH, T3, T4, testosterona, estradiol, LH e FSH foram normais(33).

Os achados encontrados assinalam que os pacientes de Itabaianinha apresentavam fenótipo clínico clássico e o padrão hormonal característico da deficiência isolada de GH tipo IB.

\section{Conclusão}

Concluímos que os pacientes avaliados apresentam DIGH tipo IB, confirmada através de dois testes de estímulos farmacológicos não-responsivos, e níveis baixos de IGF-I e IGFBP-3. Foram afastados outros distúrbios hormonais e patologias que pudessem contribuir com a referida baixa estatura nessa população.

\section{Referências}

I.AGUIAR-OLIVEIRA, M. H. et al. Effect of severe growth hormone $(\mathrm{GH})$ deficiency due to a mutation in the $\mathrm{GH}$-releasing hormone receptor on insulin-like growth factors (IGFs), IGFbinding proteins, and ternary complex formation throughout life.J Clin Endocrinol Metab, v. I48, n. 4, p. 427-32, 1999.

2. BAUMANN, G.; MACHESHWARI, H. Dwarfs of Sindh: severe growth hormone $(\mathrm{GH})$ deficiency caused by a mutation in the $\mathrm{GH}$ - releasing hormone receptor gene. Acta Peadiat, n. 423, p. 33-8, 1997.

3. BAUMANN, G.; SHAW, M.; AMBURN, K.A second lower affinity growth hormone-binding protein in human plasma. J Clin Endocrinol Metab, v. 70, p. 680-6, 1990.

4. BLUM, W. F.; RANKE, M. B.; KIETZMANN, K. A specific radioimmunoassay for the $\mathrm{GH}$ dependent somatomedin binding protein: its use for the diagnosis of $\mathrm{GH}$ deficiency. Clin Endocrinol Metab, v. 70, p. 1292-8, 1990.

5. CIANFARANI, S. et al. Is IGF binding protein-3 assessment helpful for diagnosis of $\mathrm{GH}$ deficiency? Clin Endocrinol, v. 43, n. 43-7, 1995.

6. CONGAN, J. D. W. W. et al. The PROP 1-2-by deletion is a common cause of combined pituitary hormone deficiency. J Clin Endocrinol Metab, n. 83, p. 3346-9, 1998.

7. DAVIES, P.; COLE, T. Body corporation techniques in health and disease. Cambridge, 1995.

8. DE A. BARRETTO, E. S. et al. Serum leptin and body composition in children with familial GH deficiency (GHD) due to a mutation in the growth hormone-releasing hormone $(\mathrm{GHRH})$ receptor. Clin Endocrinol, v. 5I, n. 5, p. 559-64, 1999.
9. GODFREY, P.; RAHAL, J.; BEAMER, W. G. GHRH receptor of little contains a missense mutation in the extra cellular domain that disrupts receptor function. Nature Genetics, n. 4, p. 227-32, 1993.

10. HASEGAWA, Y. et al. Reproducibility of GH stimulation tests (arginine and insulin), IGF-I and IBFBP-3 messurements. Clin Pediatr Endocrinol, n. 2, p. 75-8, 1993.

I I. ILLIG, R. Growth hormone antibodies in patients treated with different preparations of human growth hormone. J Clin Endocrinol, n. 31 , p. 679-88, 1970.

12. JANSSON, J. et al. Receptor associated resistance to growth hormone-releasing factor in dwarf little mice. Science, $n$. 232, p. 5 । I-2, 1986

13. JELLIFFE, D. B.; JELLIFFE, E. P. Anthopometric reference data: science, selection and suitability. Child Growth Standards, cap. 3, p. 66-77, 1980.

14. JONES, J.; CLEMMONS, D. R. Insulin: like growth factors and their binding proteins biological actions.J Clinical Endocrinol, n. 15, p. 70I-2I, 1995.

I5. LI, S. et al. Dwarf locus mutants lacking three pituitary cell types result from mutations in the POU - domain gene PIT-I. Nature, n. 347, p. 528-33, 1990.

16. LIN, S.; LIN, C. R.; GUKOVSKY, I. Molecular basis of the little mouse phenotype and implications for cell-type specific growth. Nature, n. 364, p. 209-14, 1993.

17. MARGARET, C. S. B; CÉSAR, L. B. Bases moleculares da deficiência do hormônio do crescimento. Arquivo Brasileiro de Endocrinologia e Metabologia, v. 4, n. 47, p. 36-7, 2003. 
18. NETCHINE, I. et al. Extensive phenotypic analysis of a family with growth hormone $(\mathrm{GH})$ deficiency caused by a mutation in the GH-releasing hormone gene. J Clinical Endocrinology Metab, n. 83, p. 432-6, 1998.

19. NISHI,Y. et al. Isolated human hormone deficiency due to hGHI dene deletion with and without hGH antibody formation during GH therapy. Acta Endocrinology, n. 122, p. 267-71, 1990.

20. OLIVEIRA, H. A. et al. Magnetic resonance imaging study of pituitary morphology in subjects homozygous and heterozygous for a null mutation of the GHRH receptor gene. Eur Jndocrinol, v. 4, n. I 48, p. 427-32, 2003.

21. OSÓRIO, M. G. F. et al. Combined pituitary hormone deficiency caused by a novel mutation of a highly pituitary conserved residue(F88S) in the homeodomain of PROP-I. J Clin Endocrinol Metabol, n. 85, p. 2779-85, 2000.

22. PARKS, J. S. Molecular biology of growth hormone. Acta Pediat, n. 349, p. 127-35, 1989.

23. PHILLIPS III, J.A. et al. Defect on growth genes. Clinical Syndromes. NY: Plum Press, 1986. p. 21 1-26.

24. PHILLIPS III, J.A. Regulation and defects in expression of growth hormone genes. Excerpt medica, n. 78, p. II-27, 1978.

25. PHILLIPS III, J. A.; CONGON, J. D. Genetic basis of endocrine disease molecular of familial human growth hormone deficiency. J Clin Endocrinol, n. 78, p. II-5, 1994.

26. PHILLIPS III, J. A.; SEEBURG, P. H.; ZACGAMANN, M. Molecular bases for familial isolated growth hormone deficiency. Proc Natl Sci USA, n. 78, p. 6372-5, 1981.

27. PREECE, M. A.; LAW, C. M.; DAVIES, P. S. W. The growth of children with paediatric disease. Clin in Endocrinol and Metabolism, n. 15, 1986.

28. RANKE, M. B.; ARONSON, A. S. Adult heigh in children with constitucional short stature. Acta Pediatr, n. 362, p. 27-31, 1989.

29. RIMODIN, D. L.; HORTON,W.A. Short Stature. Journal Pediatric, n. 92, p. 523-8, 1978.

30. ROSENFELD, R. G. et al. Diagnostic controversy: the diagnosis of children growth hormone deficiency revisited. J Clin Endocrinol, n. 80, p.I532-40, 1995.
3।.ROSENFELD, R. G; ROSENBLOOM,A. L.; GUEVARA-AGUIRRE, J. Growth hormone insensitivity due to primary $\mathrm{GH}$ receptor deficiency. Endocrinol, n. 15, p. 552-7, 1994.

32. SALVATORI, R. et al. Detection of a recurring mutation in the human growth hormone-releasing hormone receptor gene. Clin Endocrinol, n. 57, p. 77-80, 2002.

33. SALVATORI, R. et al. Familial dwarfism due to a novel mutation of the growth hormone releasing hormone receptor gene. J Clin Endocrinol Metab, n. 84, p. 917-23, 1999.

34. SAVAGE, M. O. et al. Clinical features and endocrine status in patients with growth hormone insensitivity (Laron syndrome). J Clin Endocrinol, n. 77, p. 5, 1993.

35. SORNSON, M.W. et al. Pituitary lineage determination by the Prophet of Pit-I homeodomain factor defective in Ames dwarfism. Nature, n. 384, p. 327-33, 1996.

36. TAKEUCHI, T. et al. Molecular mechanism of growth hormone $(\mathrm{GH})$ deficiency in the spontaneous dwarf rat: delection of abnormal splicing of $\mathrm{GH}$ messenger ribonucleic acid by polymerase chain reaction. Endocrinology, n. 126, p. 31-8, 1990.

37.TAR, A. Evaluation of the growth hormone-binding proteins in human plasma using high pressure liquid chromatography gel filtration. J Clin Endocrinol, n. 7I, p. 1202-7, 1990.

38. TELLER, W. M. Genetic disorders of the anterior pituitary gland. Endocrine Genetic and Genetics for Growth, n. 991, p. 91-102, 1985.

39. THISSEN, J. P.; UNDERWOOD, L. E. Nutritional regulation of the insulin-like growth factors. Endocrine Reviews, n. I3, p. 80-101, 1994.

40. TILLMANN, V. et al. Biochemical tests in the diagnosis of childhood growth hormone deficiency. J Clin Endocrinol Metab, n. 82, p. 531-5, 1997.

4I. WAJNRAJCH, M. P. et al. Nonsense mutation in the human growth hormone-releasing hormone receptor causes growth failure analogous to the little (lit) mouse. Nature Genetics, n. 12, p. 88-90, 1996.

42.WU,W. C. J. et al. Mutations in PROP-I cause familial combined pituitary hormone deficiency. Nature Genetics, n. 18, p. 147-9, 1998. 